\title{
Keeping your top players on the pitch: the key to football medicine at a professional level
}

\author{
Jan Ekstrand 1,2,3
}

The risk of injury in professional football has been estimated at about 1000 times greater than for typical industrial occupations generally regarded as high risk. ${ }^{1}$ Hence, prevention of injury in football should be of the utmost importance, and conducting injury surveillance studies is the fundamental first step in the process of prevention. ${ }^{2}$

\section{INTERNATIONAL FOOTBALL ORGANISATIONS ARE CONCERNED ABOUT THE HEALTH OF PLAYERS}

The worldwide football organisation Federation of International Football Association (FIFA) and the Union of European Football Association (UEFA) and many national federations have all observed a high risk of injury in football and have initiated and supported research with the aim of avoiding injuries and keeping players on the pitch.

In this issue, you will discover important findings of the UEFA Champions League (UCL) injury study. However, the UCL study is limited to men's professional football in Europe, which is only one part of football over the whole world.

FIFA and its research department, F-Medical Assessment and Research Centre, have carried out many studies of great importance for football overall over a period of 18 years. Two such studies are presented. Bizzini, Junge and Dvorak (see page 803) provide an overview of the development, scientific evaluation and dissemination of FIFA's injury prevention programmes, FIFA 11 and $11+$. In these studies, FIFA has demonstrated how simple exercise-based programmes can decrease the incidence of injuries in youth and amateur players. Further, FIFA has systematically documented all injuries in world football tournaments since 1998. Junge and Dvorak present an overview of these surveys indicating that the injury

\footnotetext{
${ }^{1}$ Division of Community Medicine, Department of Medical and Health Sciences, Linköping University, Linköping, Sweden; ${ }^{2}$ Football Research Group, Linköping University, Linköping, Sweden; ${ }^{3}$ UEFA Medical Committee, Nyon, Switzerland
}

Correspondence to Professor Jan Ekstrand, Solstigen 3, S-589 43, Linköping, Sweden. jan.ekstrand@telia. com incidence at matches might be influenced by the playing style, intensity of the match and refereeing (see page 782).

\section{UEFA UCL INJURY STUDY}

In 2001, UEFA initiated a research project with the aim of reducing the number and severity of injuries in football and consequently increasing the safety of players. This research project is the result of several years of work by the UEFA Medical Committee, and was preceded by discussions within UEFA in 1999 and 2000 concerning optimal study design and definitions.

The UCL injury study has been carried out over 11 seasons, with 30 European top-level football clubs from 10 different countries having participated during this time. The data show that a professional football team can expect about 50 injuries causing time-loss from play each season, equalling two injuries per player. $^{3}$ As reported by Ekstrand et al, the impact of injuries on team performance can thus be considerable when, on average, 14\% of the squad is unavailable due to injury at any point during the season (see page 732).

\section{INJURIES CAN ONLY BE PREVENTED IF THE MEDICAL STAFF HAS INFLUENCE}

The medical team ranks poorly in the hierarchy of an elite level football teamthe major power positions belong to the managers or coaches. As demonstrated by Hägglund et al (see page 738), the performance of a team is highly influenced by the injury situation; teams that can avoid injuries and keep the players on the pitch are more successful and win more matches. The medical staff is generally considered responsible for the injury situation in a club, but being low in the club hierarchy also means that they have little influence on many of the mechanisms behind injuries.

As John Orchard wrote: "If medical skill is a key component to team success, then perhaps doctors should be treated like coaches. The good news would be that medical staff members are probably worth far more money than they are currently paid. The bad news might be that, like coaches, teams should probably be more prepared to fire their medical staff if they are underperforming." 4

Since medical issues have become increasingly important for football clubs, one way to improve the medical influence could be, as has been suggested by FIFA and UEFA, to include a medical person in the board of a club.

\section{COACHES AND CEOS NEED TO BE INVOLVED IN THE INJURY PREVENTION PROCESS, BUT HOW DO WE GET THEIR ATTENTION?}

Ekstrand et al (see page 732) present the 11-year follow-up of the UCL study revealing that rates for muscle injuries and severe injuries remain high and appear to be unaffected by traditional preventive measures. Preventive actions aiming at player factors might not be enough on the professional level, and external factors such as training load, playing style and continuity of club staff should be considered. All in all, this study underlines the necessity to communicate and cooperate with coaching and administrative staffs.

However, coaches and administrative staff are seldom interested in medical statistics; their main interest is performance (results) and economy. One possibility for medical teams to get more attention is therefore to transform medical information into tactical details. Demonstrating the effect on injuries and economy would probably create such attention. The study by Hägglund et al (see page 738) clearly unmasks how injuries and team success are correlated. Teams with fewer injuries have better results both in UEFA tournaments and in national leagues. The results from this study should provide clear motivation for coaches and managers to work together with medical teams to prevent injury.

Highlighting the economical aspects of injuries is also a way to make coaches and CEOs listen. At a meeting for team doctors participating in the UCL study, the CEO of Shakhtar Donetsk, Mr Sergei Palkin, explained that the average cost for a first team player being injured for 1 month is around 500000 Euros.

Another hot topic in elite level football is the match load and the need for recovery between matches. Bengtsson et al (see page 743 ) analysed if the number of days between matches had any effect on match results and injury risk. They showed that total injury rates and muscle injury rates were increased in matches with short recovery and that a high fixture congestion was associated with increased muscle 
injury rate in matches in the same period. However, fixture congestion had no, or very limited, influence on team performance.

\section{INFORMATION ABOUT RISK, LAY-OFF TIMES AND RECURRENCE RATES IS OF GREAT PRACTICAL USE FOR FOOTBALL MEDICAL STAFFS}

In this issue, we have three papers providing new information on this field. Waldén et al report that almost every 10th football injury was an ankle ligament injury and that the ankle ligament injury rate showed a statistically significantly decreasing trend over the 11-year study period (see page 748 ). Other important findings were that $40 \%$ of the match-related ankle sprains occurred as a result of foul play.

Lundblad et al demonstrate that medial collateral ligament (MCL) injuries are decreasing over time and this sends a positive message to medical practitioners (see page 759), indicating that injury prevention of MCL injuries is moving in a promising direction. The finding that $\mathrm{MCL}$ injuries are more frequently caused by contact and foul play will hopefully lead to referees being more observant when judging contact situations.

Gajhede-Knudsen et al reveal that Achilles tendon injuries account for $4 \%$ of the total lay-off time in a club and are more common in older players (see page 763). The findings of the study will provide practical recommendations: Players with Achilles injuries might need longer recovery periods since the reinjury risk is significantly higher after recovery periods of less than 10 days.
Team medical and coaching staff should be aware of the increased risk of Achilles problems during the preseason training period and be alert to overuse to Achilles tendons at that period.

Also, beware of the higher risk of older players suffering from muscle-tendon problems after repetitive hard training sessions.

\section{RARE INJURIES NEED TO BE COLLECTED FROM MANY TEAMS OVER MANY SEASONS}

A high-profile injury is fracture of the fifth metatarsal-some very famous players have suffered from it, and although rare, it can be career ending. Ekstrand and van Dijk describe the problem in football (see page 754). The study exemplifies the benefits of studies like the UCL injury study collecting data from many teams over several seasons and thereby getting enough data for drawing safe conclusions. A team physician in a single team can never collect such information from his own club.

\section{MUSCLE INJURIES CONSTITUTE A SUBSTANTIAL PROBLEM IN FOOTBALL: ARE WE HELPED BY CLASSIFICATION?}

Hamstring muscle injuries are the most common injury subtypes. Prognostic information is vital for the medical staff to address questions from players, coaches, managers, media and agents regarding return to play. The fact that muscle injuries present a heterogeneous group of injury types, locations, severities and sizes makes prognoses about healing times and rehabilitation difficult. The validation study demonstrates the successful implementation of the Munich muscle injury classification in elite football players. Further, it is helpful for clinicians to prognosticate return to play after muscle injury.

Our hard-working authors and the editorial team hope you enjoyed this football edition of BJSM. In this digital age, you can also find a great deal of additional information at http://bjsm.bmj.com. In the near future, more information with practical implications will also be coming up from the FIFA and UEFA sources.

\section{Competing interests None.}

Provenance and peer review Commissioned; internally peer reviewed.

To cite Ekstrand J. Br J Sports Med 2013;47: 723-724.

Accepted 17 June 2013

Br J Sports Med 2013;47:723-724.

doi:10.1136/bjsports-2013-092771

\section{REFERENCES}

1 Drawer S, Fuller CW. Evaluating the level of injury in English professional football using a risk based assessment process. Br J Sports Med 2002;36:446-51.

2 Mechelen WV, Hlobil H, Kemper H. Incidence, severity, aetiology and prevention of sports injuries. Sports Med 1992;14:82-99.

3 Ekstrand J, Hägglund $M$, Waldén M. Injury incidence and injury patterns in professional football: The uefa injury study. Br J Sports Med 2011;45:553-8.

4 Orchard JW. On the value of team medical staff: Can the "Moneyball" Approach be applied to injuries in professional football? Br J Sports Med 2009;43:963-5. 